\title{
A Green Level Measure Model of Enterprise Supply Chain based on Fuzzy Information
}

\author{
Lei Xu and Jinshuan Peng* \\ Chongqing Key Lab of Traffic System and Safety in Mountain Cities, Chongqing \\ Jiaotong University, Chongqing 400074, China \\ 37951759@qq.com,pengjinshuan@163.com \\ Corresponding Author: Jinshuan Peng, pengjinshuan@163.com
}

\begin{abstract}
Green supply chain is a key part of the enterprise supply chain. However, the green level measurement of the supply chain is multi-attribute, restricted, fuzzy and uncertain. This paper addresses the issue by proposing a green level measurement model of enterprise supply chain based on fuzzy information. In this model, an indicator system is put in place. Then, fuzzy distance and fuzzy membership degree are constructed based on attribute indicators of different green levels of the supply chain. Corresponding fuzzy information algorithm is available after attribute indicators are granted with weights. Fuzzy information suggests which green level the enterprise supply chain is in. Finally, empirical studies have proved that the model and the algorithm are effective.
\end{abstract}

Keywords: green supply chain, management performance, measure model, multi-index evaluation, fuzzy information

\section{Introduction}

With the development of science and technology and the increasing strength of enterprises, commercial development and social development have attracted much attention. Green supply chain management of enterprises has become a hot issue in relative researches [1-3]. Supply chain management provides a good guidance to the analysis of green level measurement of the enterprise supply chain. However, this analytical process involves with comprehensive environment, green design and managerial technology. It is a multi-attribute, multi-restricted and complicated fuzzy system decision and analysis process.

Scholars have already studies the green supply chain management of enterprises as well as its evaluation. They provided the research with models and methods for management performance evaluation [4-7] that have yielded fruitful results. However, factors that influence the green level measurement of the enterprise supply chain are quite fuzzy and uncertain, making existing models and methods limited. Therefore, this paper takes the advantage of fuzzy theory [8-10] and axiomatic design theory [11-13]. It combines the fuzzy distance and fuzzy membership degree with information calculation model to acquire the green level fuzzy information of the enterprise supply chain. And it acquires the optimal green level measurement results through the analysis of the fuzzy information.

\section{Index System of Enterprise Supply Chain's Green Level}

A Green level measurement of the enterprise supply chain is a multi-attribute, multirestricted and complicated fuzzy system decision and analysis process. Factors that limit the green level such as environment attribute, energy consumption attribute, and market attribute and business attribute should be taken into consideration. After the research 
analysis on relevant enterprises and consulting with experts, these four attributes are selected to compose the criterion layer. Each attribute consists of many attribute indicators, as is shown in Table 1.

Table 1. Index System of Enterprise Supply Chain's Green Level

\begin{tabular}{|c|c|c|}
\hline $\begin{array}{l}\text { indicator } \\
\text { system }\end{array}$ & criterion layer & attribute indicator \\
\hline \multirow{7}{*}{$\begin{array}{r}\text { Indicato } \\
\text { r system } C\end{array}$} & $\begin{array}{l}\text { environment } \\
\text { attribute } C_{1}\end{array}$ & $\begin{array}{l}\text { environment pollution rate } c_{11} \\
\text { utilization of green material } c_{12} \\
\text { investment in environment } \\
\text { management } c_{13}\end{array}$ \\
\hline & $\begin{array}{l}\text { energy } \\
\text { consumption } \\
\text { attribute } C_{2}\end{array}$ & $\begin{array}{l}\text { energy utilization rate } c_{21} \\
\text { resource utilization rate } c_{22} \\
\text { energy consumption of } \\
\text { products } c_{23}\end{array}$ \\
\hline & & product recovery rate $c_{24}$ \\
\hline & $\begin{array}{r}\text { market } \\
\text { attribute } C_{3}\end{array}$ & $\begin{array}{c}\text { consumer satisfaction } c_{31} \\
\text { market share } c_{32}\end{array}$ \\
\hline & \multirow{3}{*}{$\begin{array}{c}\text { business } \\
\text { attribute } C_{4}\end{array}$} & $\begin{array}{l}\text { green supply chain profit } \\
\text { margin } c_{41}\end{array}$ \\
\hline & & $\begin{array}{l}\text { product recovery efficiency } c_{42} \\
\text { Assets growth rate of green } \\
\text { supply chain } c_{43}\end{array}$ \\
\hline & & $\begin{array}{l}\text { Execution cost of green supply } \\
\text { chain } c_{44}\end{array}$ \\
\hline
\end{tabular}

\section{A Model for Calculating Fuzzy Information of Enterprise Supply Chain's Green Level}

\subsection{The Concept of Information}

As one of the two axioms in axiom design theory, information axiom thinks that the less the design information brought by all kinds of influential factors in the decision and analysis process, the better the design system is. Usually, design information $I$ of influencing factors is determined by the logarithmic function of probability of qualified design parameters in the given system.

$$
I=-\log _{2} P_{i}=\log _{2}\left(1 / P_{i}\right)
$$

If those qualified design parameters are required to be discrete variables, their probability is determined by membership degree. If they are continuous random variables, 
the probability density function $\rho(P)$ is distributed randomly. The probability $P_{i}$ is expressed as:

$$
P_{i}=\int_{a_{1}}^{a_{2}} \rho(P) d P=\rho
$$

In the expression, $a_{1}$ and $a_{2}$ are limits of the probability.

\subsection{Fuzzy Information of Environment Attributes Indicators}

Environment pollution rate is used to measure the environment pollution. The membership degree function $\varphi\left(c_{11}\right)$ of its attribute indicators is a constant value falling in [0-1]. Its attribute indicators are adverse indicators. The larger $\varphi\left(c_{11}\right)$ is, the more serious the pollution is and the more information the indicator contains. Information $I_{\varphi\left(c_{11}\right)}$ acquired by membership degree function $\varphi\left(c_{11}\right)$ is expressed as:

$$
I_{\varphi\left(c_{11}\right)}=\log _{2} \frac{1}{p}=\log _{2} e^{\varphi\left(c_{11}\right)}
$$

Utilization of green material is a key indicator of environment attribute. The larger the utilization of green material is, the less pollution there is to the environment. Like the environment pollution rate, the membership degree function $\varphi\left(c_{12}\right)$ bf its attribute indicators is also a constant value falling in [0-1]. They are positive indicators. Information acquired by membership degree function $\varphi\left(c_{12}\right)$ is expressed as:

$$
I_{\varphi\left(c_{12}(x)\right)}=\log _{2} \frac{1}{p}=\log _{2} e^{1-\varphi\left(c_{12}(x)\right)}
$$

Investment in environment management includes human resources, materials and funds input into the environment management. The value of a quantity is a fuzzy interval value and is expressed as $v\left(c_{13}\right)=\left[v_{c_{13}}^{a}, v_{c_{13}}^{b}\right]$. The fuzzy distance $d\left(c_{13}\right)$ between it and the ideal interval is expressed as:

$$
d\left(c_{13}\right)=\sqrt{\frac{\left(\left|\max _{1 \leq i \leq m}\left(\frac{\min _{1 \leq i \leq m}\left(v_{c_{13}}^{a}\right)}{v_{c_{13}}^{b}}\right)-\frac{\min _{1 \leq i \leq m}\left(v_{c_{13}}^{a}\right)}{v_{c_{13}}^{b}}\right|^{2}+\left|\max _{1 \leq i \leq m}\left(\frac{\min _{1 \leq i \leq m}\left(v_{c_{13}}^{a}\right)}{v_{c_{13}}^{a}}\right)-\frac{\min _{1 \leq i \leq m}\left(v_{c_{13}}^{a}\right)}{v_{c_{13}}^{a}}\right|^{2}\right)}{2}}
$$

In the expression, $m$ refers to the number of measurement analysis scheme.

The corresponding information $I_{\varphi\left(c_{13}\right)}$ of the indicator is:

$$
I_{\varphi\left(c_{13}\right)}=\log _{2} \frac{1}{p}=\log _{2} e^{d\left(c_{13}\right)}
$$

Comprehensive fuzzy information $I_{C_{1}}$ of environment attribute indicator is:

$$
I_{C_{1}}=w_{11} * I_{\varphi\left(c_{11}\right)}+w_{12} * I_{\varphi\left(c_{12}\right)}+w_{13} * I_{\varphi\left(c_{13}\right)}
$$

In the expression, $w_{11}$ and $w_{12}$ and $w_{13}$ are the weight of each sub-indicator.

\subsection{Fuzzy Information of Energy Consumption Attributes Indicators}

Energy utilization rate and resource utilization rate are used to measure the utilization of raw materials in energy consumption. They are fuzzy concepts that can only be described by languages and thus transformed to constant values in the interval $[0,1]$, expressed by $f\left(c_{21}\right) \quad I_{f\left(c_{21}\right)}$ and $f\left(c_{22}\right)$. Their values can be acquired by surveys and 
statistical analysis. Both are positive indicators. Their information is expressed by and $I_{f\left(c_{22}\right)}$ respectively.

$$
\begin{gathered}
I_{f\left(c_{21}\right)}=\log _{2} \frac{1}{p}=\log _{2} e^{1-f\left(c_{21}\right)} \\
I_{f\left(c_{22}\right)}=\log _{2} \frac{1}{p}=\log _{2} e^{1-f\left(c_{22}\right)}
\end{gathered}
$$

Energy consumption of products is also a fuzzy concept. It can be expressed by constant value $f\left(c_{23}\right)$, like utilization rate and resource utilization rate. As it is an adverse indicator, the information $I_{f\left(c_{23}\right)}$ is calculated as:

$$
I_{f\left(c_{23}\right)}=\log _{2} \frac{1}{p}=\log _{2} e^{f\left(c_{23}\right)}
$$

Green product recovery rate is a measurement of green material recycles. It is a fuzzy concept as well and thus needs to be expressed by constant value $f\left(c_{24}\right)$. As it is a positive indicator, the information is calculated as

$$
I_{f\left(c_{24}\right)}=\log _{2} \frac{1}{p}=\log _{2} e^{e^{2-f\left(c_{24}\right)}}
$$

The comprehensive information $I_{C_{2}}$ of energy consumption attribute indicator is:

$$
I_{C_{2}}=w_{21} * I_{f\left(c_{21}\right)}+w_{22} * I_{f\left(c_{22}\right)}+w_{23} * I_{f\left(c_{23}\right)}+w_{24} * I_{f\left(c_{24}\right)}
$$

In the expression, $w_{21}, w_{22}, w_{23}$ and $w_{24}$ are the weight of each sub-indicator.

\subsection{Fuzzy Information of Market Attributes Indicators}

Consumer satisfaction refers to what degree consumers are satisfied with the green level of the enterprise supply chain. It is usually acquired through questionnaires. A low consumer satisfaction means a large amount of information and vice versa. Consumer satisfaction is a value of a quantity in a fuzzy interval and a positive attribute indicator. Suppose the consumer satisfaction is $v_{31}=\left[v_{31}^{a}, v_{31}^{b}\right]$. As it is close to the middle of the interval, the information $I_{c_{31}}$ of consumer satisfaction can be calculated as:

$$
I_{c_{31}}=\log _{2} \frac{1}{p}=\log _{2} e^{1-\frac{v_{31}^{a}+v_{31}^{b}}{2}}
$$

Market share is to measure the market control of the green supply chain. It is an important parameter for consumers to evaluate the performance of the green supply chain. As a qualitative concept, it needs to be described by fuzzy language. The higher the market share is, the less information the system contains, and vice versa. Fuzzy language should be transformed to constant value $f\left(c_{32}\right)$ in the interval [0-1]. The information of market share is calculated as:

$$
I_{f\left(c_{32}\right)}=\log _{2} \frac{1}{p}=\log _{2} e^{1-f\left(c_{32}\right)}
$$

The comprehensive fuzzy information $I_{C_{3}}$ of market attribute indicator is:

$$
I_{C_{3}}=w_{31} * I_{c_{31}}+w_{32} * I_{f\left(c_{32}\right)}
$$

In the expression, $w_{31}$ and $w_{32}$ are the weight of each sub-indicator. 


\subsection{Fuzzy Information of Business Attributes Indicators}

Green supply chain profit margin and capital growth rate of green supply chain are key features of the business ability in the green supply chain. They are main sources of direct profits. The higher these two values are, the less information the system contains. As green supply chain profit margin and capital growth rate of green supply chain fluctuate by phase, their values of a quantity are usually fuzzy interval values and are expressed as $v_{41}=\left[v_{41}^{a}, v_{41}^{b}\right]$ and $v_{43}=\left[v_{43}^{a}, v_{43}^{b}\right]$ respectively. The information $I_{c_{41}}$ and $I_{c_{43}}$ are calculated as:

$$
\begin{aligned}
& I_{c_{41}}=\log _{2} \frac{1}{p}=\log _{2} e^{1-\frac{v_{41}^{a}+v_{41}^{b}}{2}} \\
& I_{c_{43}}=\log _{2} \frac{1}{p}=\log _{2} e^{1-\frac{v_{43}^{a}+v_{43}^{b}}{2}}
\end{aligned}
$$

Product recovery efficiency is a positive attribute indicator. Suppose $v\left(c_{42}\right)=\left[v_{c_{42}}^{a}, v_{c_{42}}^{b}\right]$, then the fuzzy distance $d\left(c_{42}\right)$ between it and the ideal interval is:

$$
d\left(c_{42}\right)=\sqrt{\left(\left|\max _{1 \leq i \leq m}\left(\frac{v_{c_{42}}^{a}}{\max _{1 \leq j \leq m}\left(v_{c_{42}}^{b}\right)}\right)-\frac{v_{c_{42}}^{a}}{\max _{1 \leq j \leq m}\left(v_{c_{42}}^{b}\right)}\right|^{2}+\left|\max _{1 \leq i \leq m}\left(\frac{v_{c_{42}}^{b}}{\max _{1 \leq j \leq m}\left(v_{c_{42}}^{b}\right)}\right)-\frac{v_{c_{42}}^{b}}{\max _{1 \leq j \leq m}\left(v_{c_{42}}^{b}\right)}\right|^{2}\right.}
$$

In the expression, $m$ refers to the number of measurement analysis scheme.

The information $I_{\varphi\left(c_{42}\right)}$ of corresponding indicator is:

$$
I_{\varphi\left(c_{42}\right)}=\log _{2} \frac{1}{p}=\log _{2} e^{d\left(c_{42}\right)}
$$

Execution cost of green supply chain is an adverse attribute indicator expressed as $v\left(c_{44}\right)=\left[v_{c_{44}}^{a}, v_{c_{4}}^{b}\right]$. The fuzzy distance $d\left(c_{44}\right)$ between it and the ideal interval is:

$$
d\left(c_{44}\right)=\sqrt{\frac{\left(\left|\max _{1 \leq i \leq m}\left(\frac{\min _{1 \leq i \leq m}\left(v_{c_{44}}^{a}\right)}{v_{c_{44}}^{b}}\right)-\frac{\min _{1 \leq i \leq m}\left(v_{c_{44}}^{a}\right)}{v_{c_{44}}^{b}}\right|^{2}+\left|\max _{1 \leq i \leq m}\left(\frac{\min _{1 \leq i \leq m}\left(v_{c_{44}}^{a}\right)}{v_{c_{44}}^{a}}\right)-\frac{\min _{1 \leq i \leq m}\left(v_{c_{44}}^{a}\right)}{v_{c_{44}}^{a}}\right|^{2}\right.}{2}}
$$

In the expression, $m$ refers to the number of measurement analysis scheme.

The information $I_{\varphi\left(c_{44}\right)}$ of corresponding indicator is:

$$
I_{\varphi\left(c_{44}\right)}=\log _{2} \frac{1}{p}=\log _{2} e^{d\left(c_{44}\right)}
$$

The comprehensive fuzzy information $I_{C_{4}}$ of business attribute indicator is:

$$
I_{C_{4}}=w_{41} * I_{c_{41}}+w_{42} * I_{\varphi\left(c_{42}\right)}+w_{43} * I_{c_{43}}+w_{44} * I_{\varphi\left(c_{44}\right)}
$$

In the expression, $w_{41}, w_{42}, w_{43}$ and $w_{44}$ are the weight of each sub-indicator. 


\subsection{Comprehensive Fuzzy Information of Supply Chain's Green Level}

Based on previous analysis, information of indicators in the criterion layer is available. Suppose the weights of different criterion layer are $W_{1}, W_{2}, W_{3}$ and $W_{4}$ respectively, the system information $I_{C}$ of green level measurement scheme about all attribute indicators in the criterion layer is:

$$
I_{C}=W_{1} * I_{C_{1}}+W_{2} * I_{C_{2}}+W_{3} * I_{C_{3}}+W_{4} * I_{C_{4}}
$$

Therefore, based on the information of the system, we can get the scheme with the highest green level, which fits:

$$
I_{C}(o)=\min \left(I_{C}(1), \mathrm{L}, I_{C}(i), \mathrm{L}, I_{C}(m)\right)=I_{C}(k)
$$

It indicates that scheme $k$ with the least information has the highest green level of the enterprise supply chain.

\section{Empirical study}

This paper takes the green level measurement of three enterprises as examples to illustrate the model and the algorithm. After surveys and statistical analysis as well as experts' opinions, the attribute indicators of green level of the supply chain as shown in Table 2.

Table 2. Attribute Indicator of Enterprise Supply Chain's Green Level

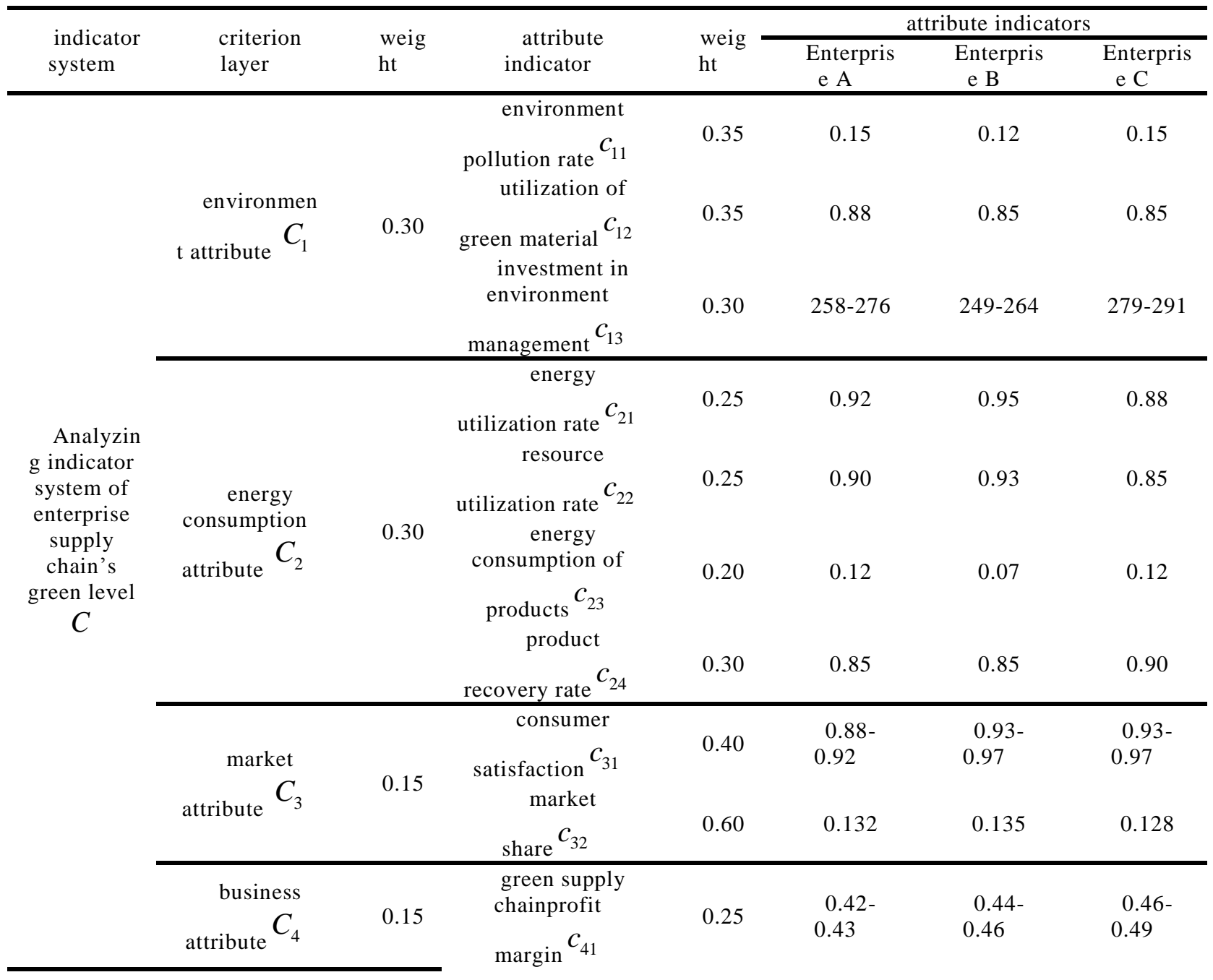




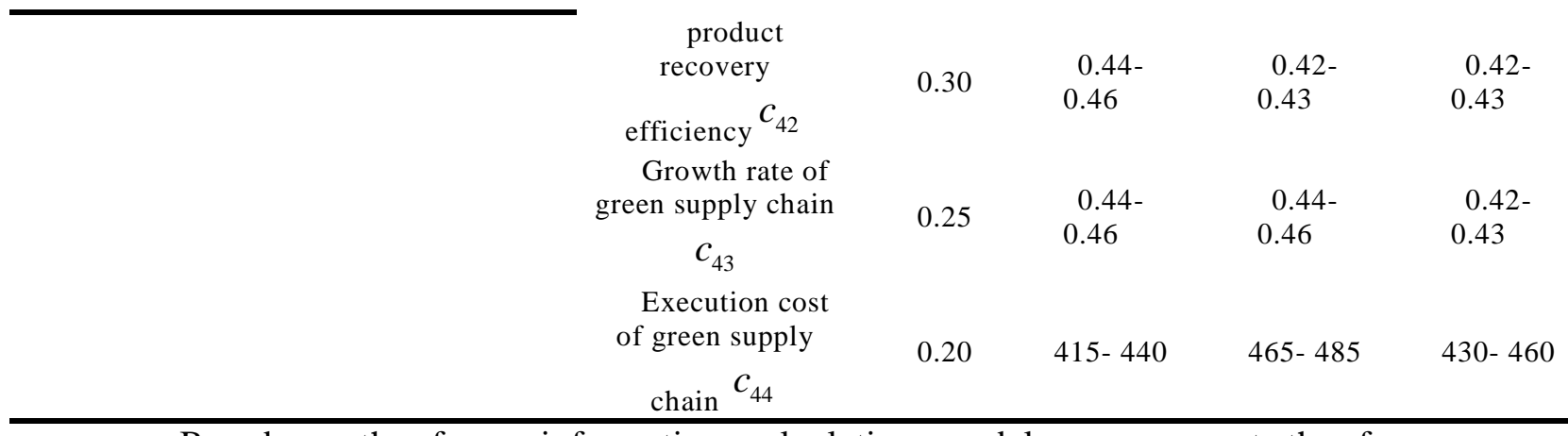

Based on the fuzzy information calculation model, we can get the fuzzy information about the green level of the supply chain of three enterprises, as is shown in Table 3.

Table 3. Fuzzy Information of Attribute Indicators of Enterprise Supply Chain's Green Level

\begin{tabular}{|c|c|c|c|}
\hline \multirow{2}{*}{ attribute indicator } & \multicolumn{2}{|l|}{$\begin{array}{r}\text { Fuzzy } \\
\text { indicator }\end{array}$} & \multirow{2}{*}{$\begin{array}{l}\text { f attribute } \\
\text { Enterpri } \\
\text { se C }\end{array}$} \\
\hline & $\begin{array}{l}\text { Enterpris } \\
\text { e A }\end{array}$ & $\begin{array}{l}\text { Enterpri } \\
\text { se B }\end{array}$ & \\
\hline $\begin{array}{l}\text { environment pollution } \\
\text { rate } c_{11}\end{array}$ & 0.216 & 0.173 & 0.216 \\
\hline $\begin{array}{l}\text { utilization of green } \\
\text { material } c_{12}\end{array}$ & 0.173 & 0.216 & 0.216 \\
\hline $\begin{array}{l}\text { investment } \\
\text { environment }\end{array}$ & 0.173 & 0.216 & 0.072 \\
\hline energy utilization rate $c_{21}$ & 0.115 & 0.072 & 0.173 \\
\hline $\begin{array}{l}\text { resource utilization } \\
\text { rate } c_{22}\end{array}$ & 0.144 & 0.101 & 0.216 \\
\hline $\begin{array}{l}\text { energy consumption of } \\
\text { products } c_{23}\end{array}$ & 0.173 & 0.101 & 0.173 \\
\hline product recovery rate $c_{24}$ & 0.216 & 0.216 & 0.144 \\
\hline consumer satisfaction $c_{31}$ & 0.144 & 0.072 & 0.072 \\
\hline market share $c_{32}$ & 0.173 & 0.144 & 0.216 \\
\hline $\begin{array}{l}\text { green supply chainprofit } \\
\operatorname{margin} c_{41}\end{array}$ & 0.216 & 0.144 & 0.072 \\
\hline $\begin{array}{cr}\text { product } & \text { recovery } \\
\text { efficiency } & c_{42}\end{array}$ & 0.144 & 0.216 & 0.216 \\
\hline Assets growth rate of & 0.144 & 0.144 & 0.216 \\
\hline
\end{tabular}




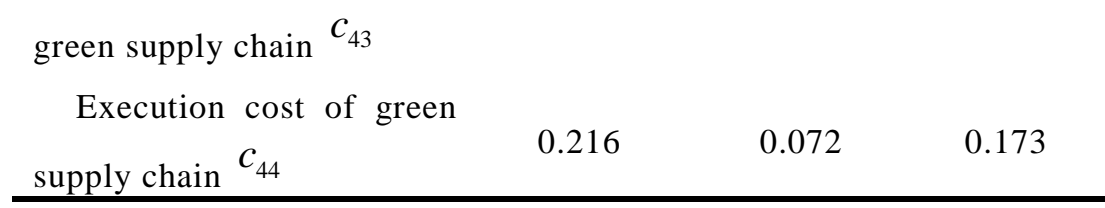

According to fuzzy information calculation model, we can get the sequence of three enterprises, namely, $I=\left(I_{C}(A), I_{C}(B), I_{C}(C)\right)=(0.174,0,142,0.167)$.Enterprise $\mathrm{B}$ has the smallest amount of information and is regarded as having the best green level of the supply chain.

\section{Conclusions}

This paper proposes a green level measurement model of enterprise supply chain based on fuzzy information. This model puts in place an indicator system after analyzing the green level attribute indicators. Then, detailed analysis is conducted through information calculation of attribute indicators based on information axiom and fuzzy information. Weight of each indicator is taken into account. Comprehensive fuzzy information is acquired based on which the optimal green level of the supply chain is determined. This model is significant in that it is calculated simply and provides a good support for computer assistance analysis on green level measurement of the supply chain.

\section{Acknowledgments}

Project supported by natural science foundation of Ningbo No. 2013A610125: A Study of Localization Algorithm for WSN Based on Beacon-Free-Node; Project supported by research foundation of Ningbo Dahongying University CF122123: A Study of the Bridging Technology of the Next-Generation Internet Based on MPLS.

\section{References}

[1]. J.Juhai, L. Qingli and G. Zhongxing, "Performance Appraisal of Green Supply Chain Management of Steel Enterprises", Science and Technology Management Research, vol. 16, (2013), pp. 53-57.

[2]. B. Shuzhen and L. Yanying, "Research on Enterprise Implementation of Green Supply Chain", Logistics Engineering and Management, vol. 3, (2013), pp. 117-119.

[3]. X.-W. Liu and Z.-G. Wang, "The performance evaluation of green supply chain of enterprise 2011 International Symposium on Applied Economics", Business and Development, vol. 8, (2011), pp. 304309

[4]. X. Xu and Y. Zhao, "Performance Evaluation for Green Supply Chain Based on Entropy Method and Fuzzy Comprehensive Evaluation”, Journal of Shanghai Dianji University, vol. 15, no. 4, (2012), pp. 276-280.

[5]. H. Zhang, T. Feng and D. Hongguo, "A Study on Performance Evaluation of Green Supply Chain Management", Journal of Information, vol. 6, (2006), pp. 42-44.

[6]. L. Lixin, L. Yan and P. Can, "Enterprises Green Degree of Green Supply Chain Management based on Fuzzy-AHP Model", Science Technology and Industry, vol. 3, (2008), pp. 1-5.

[7]. J. Li, "Performance Evaluation for Green Supply Chain Based on Property Method", Economic Engineering, vol. 12, (2011), pp. 52-54.

[8]. J. J. Zhang, D. S. Wu and D. L. Olson, "The method of grey related analysis to multiple attribute decision making problems with interval numbers", Mathematical and Computer Modelling, vol. 42, (2005), pp. 991-998.

[9]. T. Qihua, R. Xiao and Y. Zhong, et al., "Evaluation Schemes Method for Design Based on Information Axiom and Fuzzy Mathematics", Transactions Of The Chinese Society For Agricultural Machinery, vol. 39, no. 12, (2008), pp. 136-140.

[10].J. Liu and S. Liu, "Sorting of Multi-attribute Decision-making of Interval Attribute Value", Chinese Journal of Management Science, vol. 18, no. 3, (2010), pp. 90-94.

[11].X. Cheng, R. Xiao, P. Liu and Y. Xu, "Hybrid multiple attributes evaluation method for product scheme based on information axiom", Computer Integrated Manufacturing Systems, vol. 16, no. 9, (2010), pp. 1816-1822. 
[12].T. Wang, B. Chen and L. Bu, "Multi-attribute Optimal Selection Model of Large-Scale Hydraulic Turbine Scheme Design Based on Information Axiom", Journal of Nanjing University of Aeronautics and Astronautics, vol. 43, no. 6, (2011), pp. 822-826.

[13].R. Zhang, Q. Meng and L. Meng, "Fuzzy evaluation method of design plans based on information axiom", Journal of Beijing university of posts and telecommunications, vol. 35, no. 6, (2012), pp. 25-29.

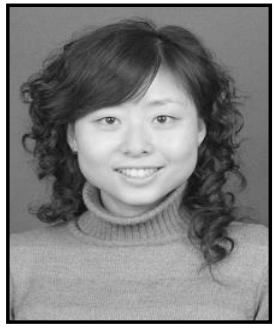

Lei Xu, Female, Doctor of Logistic Engineering, Associate Professor. She received her Ph.D. in logistic engineering (2011) from Chang'an university. Now she is an assistant professor of traffic management, Chongqing Jiaotong University. Her current research interests include E-commerce implementation evaluation and supply chain emergency management.

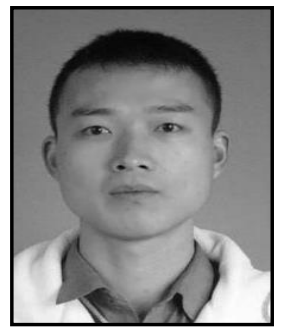

Jinshuan Peng, Male, Doctor of Engineering, Associate Professor. He received his Ph.D. in vehicle operation engineering (2012) from Chang'an university. Now he is an assistant professor of transportation, Chongqing Jiaotong University. His current research interests include driving behavior and E-commerce implementation evaluation. 
International Journal of $u-$ and $e-$ Service, Science and Technology Vol.8, No.2 (2015) 